\title{
EFEITO DE DIFERENTES SISTEMAS DE PRODUÇÃO DE MUDAS E SUBSTRATOS NO DESENVOLVIMENTO DE ENTEROLOBIUM CONTORTISILIQUUM
}

Hywre Santos SOUSA ${ }^{1}$

Hilquias dos Santos SILVA ${ }^{12}$

Douglas Santos GONÇALVES²

Patrícia Aparecida de SOUZA ${ }^{3}$

André Ferreira dos SANTOS ${ }^{4}$

\begin{abstract}
1'Acadêmico de Engenharia Florestal da Universidade Federal do Tocantins, yurii.i@uft.edu.br.
${ }^{12}$ Acadêmico de Engenharia Florestal da Universidade Federal do Tocantins, hilquiassilva@uft.edu.br.

${ }^{2}$ Mestrando do Programa de Ciências Florestais e Ambientais da Universidade Federal do Tocantins, goncalvesds@hotmail.com.

3Professora Doutora do Curso de Engenharia Florestal da Universidade Federal do Tocantins,
\end{abstract} patriciaapsouza@uft.edu.br.

${ }^{4}$ Professor Doutor do Curso de Engenharia Florestal da Universidade Federal do Tocantins, andrefs@uft.edu.br.

Recebido em: 23/04/2016 - Aprovado em: 02/11/2016 - Disponibilizado em: 18/12/2016

\section{RESUMO:}

A Enterolobium contortisiliquum é uma árvore da família Fabaceae-Mimosoideae (Leguminosae), de médio a grande porte e de crescimento rápido, encontrada em grande parte do cerrado brasileiro, mostrando-se uma espécie promissora para a implantação em áreas degradadas. O presente trabalho objetivou avaliar diferentes sistemas de planto (repicagem e semeadura direta) e diferentes substratos (terra de subsolo e terra de subsolo+areia+esterco bovino). O experimento foi conduzido no Viveiro Florestal da Universidade Federal do Tocantins, Campus de Gurupi. Os tratamentos avaliados foram: T1 (repicagem/subsolo); T2 (semeadura direta/subsolo); T3 (repicagem/areia+subsolo+esterco bovino); T4 (semeadura direta/areia+subsolo+esterco bovino). Odelineamento experimental foi o inteiramente ao acaso, com os tratamentos distribuídos em esquema fatorial $2 \times 2$ (dois sistemas de plantio e dois tipos de substratos), os tratamentos foram divididos em seis repetições e avaliados com 30, 60 e 90 dias após a germinação. Os tratamentos que tinham como substrato, areia+subsolo+esterco bovino (T3 e T4), foram os que apresentaram maiores resultados na qualidade das mudas, e que o sistema de semeadura direta é o indicado para a produção de mudas de Enterolobium contortisiliquum.

Palavras-chave: Cerrado. Preservação. Semeadura direta. Transplantio. Tamboril.

\section{EFFECT OF DIFFERENT SEEDLING PRODUCTION SYSTEMSAND SUBSTRATES ON THE DEVELOPMENT OF ENTEROLOBIUM CONTORTISILIQUUM}

\begin{abstract}
:
Enterolobium contortisiliquum is a tree of the Fabaceae-Mimosoideae family (Fabaceae), medium to large size and rapid growth, found in much of the Brazilian cerrado, being a promising species of degraded areas recovery. This study aimed to evaluate different plant systems (transplanting and direct sowing) and different substrates (subsoil and subsoil + sand + bovine manure). The experiment was conducted at the Forest Nursery of the Federal University of Tocantins,Gurupi, state of Tocantins, Brazil. The treatments were: T1 (transplanting/subsoil); T2 (direct sowing/subsoil); T3 (transplanting/sand + subsoil + bovine manure); T4 (direct sowing/sand + subsoil + bovine manure). The experimental design was completely randomized with treatments distributed in a factorial $2 \times 2$ (two planting systems and two types of substrates), the treatments were divided into six repetitions and evaluated at 30,60 and 90 days after germination. The treatments as substrate, sand + subsoil + bovine manure (T3 and T4) had the highest results in the quality of seedlings and as such, the direct sowing system is indicated for the production of seedlings of Enterolobium contortisiliquum.
\end{abstract}

Keywords: Brazilian Cerrado. Preservation. Direct sowing. Transplanting. Tamboril. 


\section{INTRODUÇÃO}

O cerrado embora seja um dos cinco maiores domínios naturais do planeta, não vem tendo prioridade em sua preservação. $\mathrm{O}$ bioma continua sendo devastado pelas vastas queimadas e pelas máquinas que penetram em seus solos sem o menor compromisso com a preservação, provocando a extinção de várias espécies nativas, algumas delas, como algumas fruteiras, nem foram ainda catalogadas (BARROS, 2009).

Este biomaapresenta grandediversidade de espécies, animais e vegetais, entre elas, Enterolobium contortisiliquum, popularmente conhecido como timburi, orelha-de-negro, orelha-demacaco, tamboril. Segundo Lorenzi (2008), é uma árvore da família Fabaceae-Mimosoideae (Leguminosae), de médioa grande porte e de crescimento rápido. Araújoet al., (2011) afirma que a espécie Enterolobium contortisiliquum é ótima para reflorestamento de áreas de preservação permanente degradadas, devido ao seu rápido crescimento inicial. No entanto, pouco se sabe sobre a produção de mudas de tamboril, o que em muitos casos leva ao insucesso as tentativas de produzir mudas destaespécie nativa do Cerrado.

Há várias formas de produzir mudas de espécies florestais, podendo ser diretamente na sementeira ou através do plantio direto em recipientes, em viveiro. $\mathrm{O}$ método de semeadura direta consiste em depositar as sementes em recipientes enquanto o método da repicagem consiste em realizar o transplante da muda de um recipiente ou sementeira para a embalagem definitiva, porém torna a produção mais cara, além de exigir mais mão de obra (SCHORN e FORMENTO, 2003).

No processo de propagação de mudas via semente, o uso de substrato tem influência sobre a emergência de plântulas, cuja função é fornecer condições ideais para o crescimento inicial e estabelecimento, refletindo diretamente na qualidade da muda e no sucesso de povoamentos florestais (BOENE et al.,, 2013).A utilização de substratos com baixo custo aliada a formação de mudas com padrão morfológico superior às demais, resulta na redução do ciclo de produção e num menor dispêndio econômico (SIMÕES et al.,, 2012).

O objetivo deste trabalho foi avaliar o efeito de diferentes sistemas de produção de mudas e substratos no desenvolvimento de mudas de Enterolobium contortisiliquum, para a recuperação de áreas degradadas no Cerrado.

\section{MATERIAL E MÉTODOS}

O experimento foi conduzido no mês de novembro de 2015 a fevereiro de 2016 . No 
Viveiro da Universidade Federal do Tocantins (UFT), Campus Universitário de Gurupi, localizado na região sul do estado do Tocantins (figura 1 ), a $11^{\circ} 43^{\prime} \mathrm{S}$ e $49^{\circ} 04^{\prime} \mathrm{W}$, a $280 \mathrm{~m}$ de altitude. Clima tropical úmido com pequena deficiência hídrica $\left(B 1 w A^{\prime} a^{\prime}\right)$, a temperatura média anual é de $29,5{ }^{\circ} \mathrm{C}$, com precipitação anual média de $1804 \mathrm{~mm}$, sendo um verão chuvoso e um inverno seco. Savana tropical $(A w)$ por Köppen - Geiger (PEEL, 2007).

Figura 1 -Localização do município de Gurupi-TO

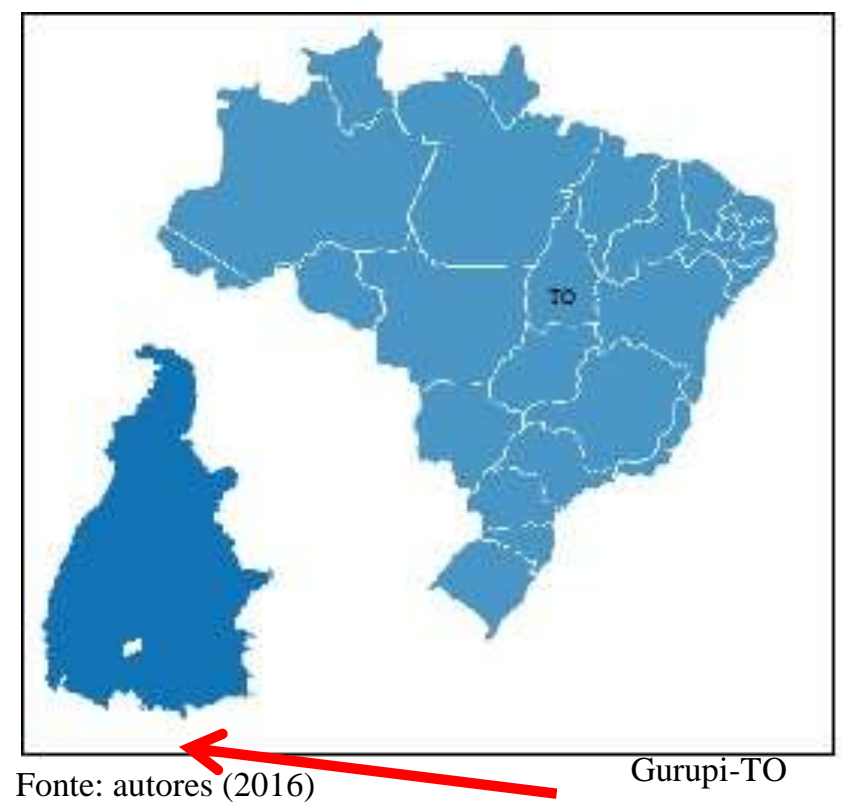

Foram colhidas no município de Peixe-TO, BR 153, frutos de $E$. contortisiliquum de árvores matrizes. Depois do processo de beneficiamento e antes de serem colocadas para germinar, as sementes foram submetidas a um tratamento prégerminativo para superação de dormência em água fervente (IAF), $100^{\circ} \mathrm{C}$ por 3 minutos, de acordo com as Regras para Análise de Sementes (BRASIL, 2009) para homogeneizar a germinação.Foram testados quatro tratamentos com suas respectivas proporções indicados na Tabela 1.0 experimento foi conduzido em DIC fatorial $2 \times 2$ com total de 6 repetições.

Tabela 1 -Descrição dos substratos e suas respectivas proporções em volume para cada tratamento.

\begin{tabular}{|c|c|c|}
\hline Tratamentos & Substratos & Proporção em volume \\
\hline T1 (Repicagem) & TS: Terra de subsolo & \\
\hline T2 (Semeadura direta em saco plástico) & TS: Terra de subsolo & $(1: 1: 1)$ \\
\hline T3 (Repicagem) & AR + TS + EB: (areia + terra de subsolo + esterco bovino) & $(1: 1: 1)$ \\
\hline T4 (Semeadura direta em saco plástico) & AR + TS + EB: (areia + terra de subsolo + esterco bovino) & \\
\hline
\end{tabular}

Fonte: autores (2016)

A areia foi adquirida comercialmente na região de Gurupi-TO. A terra de subsolo e o esterco bovino foram coletados na Universidade Federal do Tocantins. No tratamento oriundo de repicagem, as sementes foram semeadas em sulcos na sementeira, no Viveiro Florestal e após a emergência, que ocorreu8 dias após o plantio, e foram 
transplantadas para os sacos plásticos de $15 \times 25 \mathrm{~cm}$. Os tratamentos foram colocados casa de sombra(30\%). Para a semeadura direta foram utilizados sacos de polietileno de $15 \times 25 \mathrm{~cm}$ colocando-se três sementes por recipientes. Após a germinação, aos 10 dias, foram retiradas duas plântulas, restando apenas uma por recipiente.A irrigação foi por aspersão, duas vezes ao dia.

Foram avaliados os parâmetros: a) altura da planta (AP) com régua graduada em centímetros (cm); b) diâmetro do colo (DC) a $5 \mathrm{~mm}$ do solo, com paquímetro eletrônico graduado em milímetros $(\mathrm{mm}) ; \mathrm{c})$ massa verde da parte aérea (MVPA); d) massa verde da raiz (MVR), e) massa seca radicular (MSR); f) massa seca aérea (MSA); e avaliou-se também oÍndice de Qualidade de Dickson(IQD).

Após 90 dias da implantação do experimento, as mudas foram separadas em parte aérea e radicular, para determinação da massa seca, as raízes foram submetidas a lavagem em água corrente, utilizando-se peneiras de malha fina, para evitar a perda de raízes eos nódulos presentes nas raízes. A obtenção das massas foi realizada separadamente, acondicionando em sacos de papel do tipo Kraft devidamente identificados, pesados e colocados em estufa com circulação de ar forçada, à aproximadamente $75^{\circ} \mathrm{C}$, durante 72 horas.
Posteriormente as amostras foram pesadas em balança analítica eletrônica a $(0,01 \mathrm{~g})$.

O Índice de Qualidade do Dickson (IQD), é uma metodologia para calcular o Índice de Qualidade de Desenvolvimento, elaborada por Dicksonet al., (1960), esse índice é um bom indicador da qualidade das mudas, pois no seu cálculo são consideradas os indicadores de massa seca da parte aérea, das raízes e da massa seca total da planta, altura e diâmetro do colo das mudas ponderando os resultados de vários parâmetros importantes empregados para avaliação da qualidade (FONSECA et al., 2002), pelo uso da equação:

$$
I Q D=\frac{M S T}{\frac{h}{D C}+\frac{P M S P A}{P M S P R}}
$$

Onde:IQD = Índice de desenvolvimento de Dickson, MST = Massa seca total $(\mathrm{g}), \mathrm{h}=$ altura $(\mathrm{cm}), \mathrm{DC}=$ diâmetro do colo $(\mathrm{cm})$, PMSPA = Peso da matéria seca da parte aérea $(\mathrm{g})$ e PMSPR = Peso da matéria secada raiz $(\mathrm{g})$.

Os dados obtidos foram tabulados no programa EXCEL. Os tratamentos foram submetidos à análise de variância, e as médias comparadas pelo teste Tukey $(\mathrm{p}=0,01)$, utilizando-se o software ASSISTAT versão 7.7 beta (SILVA, 2015).

\section{RESULTADOS E DISCUSSÃO}

De acordo com a análise de variância, não houve diferença significativa dos diferentes tratamentos após 30 dias quanto à 
altura da planta (AP), já quanto a diâmetro do colo (DC) apenas o tratamento de semeadura direta com subsolo (T2) e repicagem com areia + terra de subsolo + esterco bovino (T3) mostraram-se inferiores aos demais tratamentos (Tabela 2).

Aos 60 dias, a altura da muda não apresentou diferença significativa entre os tratamentos utilizados.No que se refere a diâmetro do colo da muda, após 60 dias, o tratamento de semeadura de direta com areia
+ terra de subsolo + esterco bovino apresentou diferenças significativas, dos demais tratamentos (Tabela 2).

Após 90 dias, não houve diferença significativa entre o tratamento de repicagem com areia + terra de subsolo + esterco bovino (T3) e T4 para altura;o tratamento T4 apresentou maiores médias no que se refere a diâmetro do coleto, mostrando-se eficiente para o desenvolvimento da espécie (Tabela 2).

Tabela 2 - Altura de plantas (AP) e diâmetro de colo (DC) de mudas de E. contortisiliquum produzidas em diferentes sistemas de produção de mudas e substratos aos 30, 60 e 90 dias.

\begin{tabular}{|c|c|c|c|c|c|c|}
\hline \multirow{2}{*}{ Tratamentos } & \multicolumn{2}{|c}{ 30 dias } & $\mathbf{6 0}$ dias & \multicolumn{2}{c|}{$\mathbf{9 0}$ dias } \\
\cline { 2 - 7 } & $\mathbf{A P}(\mathbf{c m})$ & $\mathbf{D C}(\mathbf{m m})$ & $\mathbf{A P}(\mathbf{c m})$ & $\mathbf{D C}(\mathbf{m m})$ & $\mathbf{A P}(\mathbf{c m})$ & $\mathbf{D C}(\mathbf{m m})$ \\
\hline $\mathbf{T} 1$ & $13,46 \mathrm{a}$ & $2,69 \mathrm{a}$ & $30,58 \mathrm{a}$ & $2,76 \mathrm{~b}$ & $44,00 \mathrm{~b}$ & $4,19 \mathrm{~b}$ \\
\hline $\mathbf{T} 2$ & $13,20 \mathrm{a}$ & $2,63 \mathrm{ab}$ & $28,41 \mathrm{a}$ & $2,70 \mathrm{~b}$ & $40,08 \mathrm{~b}$ & $4,06 \mathrm{~b}$ \\
\hline $\mathbf{T 3}$ & $14,06 \mathrm{a}$ & $2,34 \mathrm{~b}$ & $27,50 \mathrm{a}$ & $2,60 \mathrm{~b}$ & $73,56 \mathrm{a}$ & $2,70 \mathrm{c}$ \\
\hline $\mathbf{T} 4$ & $11,58 \mathrm{a}$ & $2,80 \mathrm{a}$ & $35,33 \mathrm{a}$ & $3,15 \mathrm{a}$ & $86,78 \mathrm{a}$ & $6,77 \mathrm{a}$ \\
\hline $\mathbf{C V}(\%)$ & 15,87 & 7,93 & 19,08 & 7,13 & 16,37 & 10,73 \\
\hline
\end{tabular}

Médias seguidas de mesma letra nas colunas não diferem estatisticamente pelo teste Tukey(p $\leq 0,01)$.

Gomeset al., (2002) ao avaliar a qualidade de mudas de Eucalyptusgrandis, enfatiza que a altura da planta apresenta uma primordial contribuição para uma avaliação da qualidade de mudas, sendo essas características fáceis e viáveis de mensuração, além de não destruir a planta.Os menores valores de altura e diâmetro foram observados nos tratamentos que continham somente terra de subsolo como substrato (T1 e T2), ou seja, o sistema de produção (repicagem ou semeadura direta) não influenciou nos resultados.
$\mathrm{O}$ esterco - presente nos tratamentos T3 e T4 - também utilizado por Correia et al., (2001) como substrato na produção de Annonamuricata, é um componente orgânico que, utilizado em associação a outros, por exemplo areia e terra de subsolo, melhora as condições físicas do substrato, como aeração e drenagem, além de ser rico em nutrientes, que são rapidamente liberados para as plantas, quando curtido.

Observou-se que ocorreu uma acentuada formação de nódulos no sistema 
radicular, presente em muitas espécies da família Fabaceae. Esses nódulos são responsáveis pela atividade simbiótica com bactérias fixadoras de nitrogênio, o que pode auxiliar na nutrição da muda durante o processo de produção (ABREUet al $\backslash 2015$ ), o que para Garciaet al., (2011) também facilita sua regeneração até mesmo em solos mais pobres ou degradados.
Avaliando a matéria verde, em semeadura direta em saco plástico composto por areia + terra de subsolo + esterco bovino (T4), obteve o melhor resultado estatístico comparado a T3 que foi realizado pelo sistema de repicagem, utilizando o mesmo substrato de T4. Os menores resultados foram em T1 (repicagem: subsolo) e T2 (semeadura direta em saco plástico: subsolo),(Tabela 3).

Tabela 3 -Massa úmida da parte aérea (MUPA), massa úmida de raízes (MUR), massa seca da parte aérea (MSPA), massa seca de raízes (MSR), e Índice de Qualidade de Dickson (IQD) de E. contortisiliquum produzidas em diferentes sistemas de produção de mudas e substratos aos 90 dias.

\begin{tabular}{|c|c|c|c|c|c|}
\hline Tratamentos & MVPA $(\mathbf{g})$ & MVR $(\mathbf{g})$ & MSPA $(\mathbf{g})$ & MSR $(\mathbf{g})$ & IQD \\
\hline T1 & $6,90 \mathrm{c}$ & $8,56 \mathrm{c}$ & $2,49 \mathrm{c}$ & $2,37 \mathrm{c}$ & $0,43 \mathrm{~b}$ \\
\hline T2 & $7,29 \mathrm{c}$ & $10,81 \mathrm{c}$ & $2,38 \mathrm{c}$ & $3,33 \mathrm{bc}$ & $0,56 \mathrm{~b}$ \\
$\mathbf{T 3}$ & $22,76 \mathrm{~b}$ & $23,29 \mathrm{~b}$ & $7,94 \mathrm{~b}$ & $6,06 \mathrm{~b}$ & $0,48 \mathrm{~b}$ \\
\hline $\mathbf{T 4}$ & $32,35 \mathrm{a}$ & $34,75 \mathrm{a}$ & $10,59 \mathrm{a}$ & $9,15 \mathrm{a}$ & $1,39 \mathrm{a}$ \\
\hline $\mathbf{C V}(\%)$ & 26,43 & 31,43 & 27,24 & 33,75 & 29,09 \\
\hline
\end{tabular}

Médias seguidas de mesma letra nas colunas não diferem estatisticamente pelo teste Tukey(p $\leq 0,01)$.

Para Souza et al., (1995) que avaliaram diferentes substratos para cultivo de Chrysanthemum morifolium, o maior desenvolvimento pode estar relacionado ao fato de que matéria orgânica (MO) pode favorecer ofornecimento de parte dos nutrientes às mudas e também retenção de umidade, proporcionando vigor as mudas, em relação asque não utilizam $\mathrm{MO}$ em sua composição.

A massaverdeda parte aérea e de raízes das mudas foiestatisticamente superior no sistema de semeadura direta no tratamento T4; o peso da raiz seca obteve resultados inferiores em sistema de repicagem e semeadura direta com TS (T1 e T2), não havendo diferença significativa no desenvolvimento em relação ao sistema de produção e substrato em T2 e T3 (Tabela 3), sendo o tratamento $\mathrm{T} 4$ superior estatisticamente.

A MSPA e MSR nos substratos contendo apenasTS (T1 e T2), observou-se que as raízes se apresentaram em menor número e desenvolvimento, tanto com relação ao número de raízes quanto tamanho e espessura.Silvaet al., (2009), ao estudar o desenvolvimento da Hancornia speciosa, observaram que ao incrementar o substrato com esterco estimulou a produção de peso das raízes secas.

De acordo com o Índice de Qualidade de Dickson, o tratamento T4(areia + terra de 
subsolo + esterco bovino) se apresentou tendo os melhores resultados estatisticamente, em relação aos demais tratamentos. Saidelles et al., (2009) também obteve resultados satisfatórios em relação ao IQD tendo no substrato o uso de $50 \%$ de subsolo mais $50 \%$ de casca de arroz carbonizada como componentes para produção de Enterolobium Contortisiliquum. Araújoet al., (2011)observaram que o peso da biomassa das mudas de Enterolobium Contortisiliquum é influenciado pela adição de uma fonte orgânica de nutriente - neste caso, esterco bovino curtido - sendo que, asua adição ao solo proporciona maior retenção de água, melhor a aeração das raízes e fornece nutrientes para a muda. Embora, Caldeiraet al., (2008) afirmem que a utilização de um substrato com elevado teor de matéria orgânica, seja ele esterco bovino ou outros elementos, as mudas tenderão a apresentar um

\section{REFERÊNCIAS}

ABREU, A. H. M.et al., Produção de mudas e crescimento inicial em campo de

Enterolobium contortisiliquum produzidas em diferentes recipientes. Floresta, v. 45, n. 1, p. 141-150, 2015.

ARAÚJO, A. P.; PAIVA SOBRINHO, S.. Germinação e produção de mudas de tamboril (Enterolobium Contortisiliquum (Vell.) Morong) em diferentes substratos.Rev. Árvore, Viçosa, v. 35, n. 3, supl. 1, p. 581588, 2011.

BARROS, F. S. A ação do homem no processo de destruição do Cerrado. Trabalho crescimento menor, devido supostamente a maior microporosidade nesses materiais, diminuindo a aeração, na qual afeta o desenvolvimento das raízes das mudas.

\section{CONCLUSÕES}

- O desenvolvimento das mudas no tratamento de semeadura direta em saco plástico contendo substrato de areia + terra de subsolo + esterco bovino foi melhor que o tratamento com repicagem utilizando os mesmo substratos.

- Os tratamentos que não continham esterco bovino na composição apresentaram os menores valores nos resultados, independente do sistema de produção (repicagem ou semeadura direta emsaco plástico).

de conclusão de Curso de Geografia.

Faculdade Projeção. Taguatinga - DF, 2009.

BOENE HCAM et al.,. Efeitos de diferentes substratos na produção de mudas de Sebastiania commersoniana. Floresta 43 : 407-420, 2013.

BRASIL. Ministério da Agricultura, Pecuária e Abastecimento. Secretaria de Defesa Agropecuária. Regras para análise de sementes. Brasília: 2009.

CALDEIRA, M.V.W.; et. al. Composto orgânico na produção de mudas de aroeiravermelha. Scientia Agraria, Curitiba, v.9, n.1, p. 27-33, 2008. 
CORREIA, D.; CAVALCANTI JÚNIOR, A. T.; COSTA, A. M. G. Alternativas de substratos para a formação de portaenxertos de gravioleira (Annonamuricata) em tubetes. Fortaleza: Embrapa Agroindústria Tropical, 2001. (Comunicado Técnico, 67).

DICKSON, A.; LEAF, A.L.; HOSNER, J.F. Quality appraisal of white spruce and white pine seedling stock in nurseries.Forest Chronicle, v. 36, p.10-13, 1960.

FONSECA, É. P.; VALÉRI, S. V.; MIGLIORANZA, É.; FONSECA, N. A. N.; COUTO, L. Padrão de qualidade de mudas de Trema micrantha (L.) Blume, produzidas sob diferentes períodos de sombreamento.

Revista Árvore, Viçosa, v. 26, n. 4, p. 515523, 2002.

GARCIA, C. C.; REIS, M. G. F.; REIS, G. G.; PEZZOPANE, J. E. M.; LOPES, H. N. S.; RAMOS, D. C. Regeneração natural de espécies arbóreas em fragmento de floresta estacional semidecidual Montana, no domínio da Mata Atlântica, em Viçosa, MG. Ciência Florestal, Santa Maria, v. 21, n. 4. Minas Gerais, 2011.

GOMES, J. M. et al., Parâmetros morfológicos na avaliação da qualidade de mudas de Eucalyptusgrandis. Revista Árvore, v.26, n.4, p.515-523, 2002.

LORENZI, H. Árvores Brasileiras: Manual de Identificação e Cultivo de Plantas Arbóreas Nativas do Brasil, v. 01, $5^{\text {a }}$ ed. Nova Odessa, São Paulo: Instituto Plantarum, 2008. 384p.

PEEL, M. C., FINLAYSON, B. L., and MCMAHON, T. A.: Updated world map of the Köppen-Geiger climate classification, Hydrol. Earth Syst. Sci., 11, 1633-1644, doi:10.5194/hess-11-1633-2007, 2007.

SAIDELLES, F. L. F. et al.,Casca de arroz carbonizada como substrato para produção de mudas de tamboril-da-mata e garapeira.

Semina: Ciências Agrárias, v.30, p. 11731186, 2009.
SCHORN, L.A.; FORMENTO, S. Produção

de mudas florestais. Blumenau:

Universidade Regional de Blumenau, Centro de Ciências Tecnológicas, Departamento de Engenharia Florestal, 55 p, 2003.

SILVA, E. A. et al., Efeito de diferentes substratos na produção de mudas de mangabeira (Hancorniaspeciosa). Revista

Brasileira de Fruticultura, v.31, n.3, p.925929, 2009.

SILVA, F. de. A. S., 2015. ASSISTAT: Versão 7.7 beta. DEAG-CTRN-UFCG Atualizado em 01 de abril de 2015. Disponível em <http://www.assistat.com/>. Acesso em: 10 de mar. de 2016.

SIMÕES; D.; SILVA, R. B. G da.; SILVA, M. R da. Composição do substrato sobre o desenvolvimento, qualidade e custo de produção de mudas de Eucalyptusgrandis Hill ex Maiden x Eucalyptusurophylla S. T. Blake. Ciência Florestal, v. 22, n. 1, p. 91- 100. 2012.

SOUZA, M. M.; LOPES, L. C.; FONTES, L. E. F. Avaliação de substratos para o cultivo de crisântemo (Chrysanthemummor ifolium Ramat. ,Compositae) 'White Polaris' em vasos. Revista Brasileira de Horticultura Ornamental, v.1, n.2, p.71-77, 1995. 